Chronic Obstructive Pulmonary Diseases: Journal of the COPD Foundation

\author{
Original Research
}

\title{
Efficacy of Indacaterol/Glycopyrronium in Patients with COPD Who Have Increased Dyspnea with Daily Activities
}

\author{
Donald A. Mahler, MD ${ }^{1}$ Dorothy L. Keininger, $\mathrm{MSc}^{2}$ Karen Mezzi, MD ${ }^{2}$ Robert Fogel, MD ${ }^{3}$ Donald Banerji, MD $^{3}$
}

\section{Abstract}

Introduction: The Global initiative for chronic Obstructive Lung Disease (GOLD) recommends treating patients with chronic obstructive pulmonary disease (COPD) based on a combined assessment of symptom severity and airflow limitation and/or exacerbation risk. According to GOLD, patients with mild-to-moderate airflow limitation and distressing symptoms such as dyspnea should be treated with a long-acting beta2-agonist (LABA) or a longacting muscarinic antagonist (LAMA). If symptoms persist on monotherapy, GOLD recommends a combination of bronchodilators (LABA/LAMA).

Methods: We performed a post-hoc analysis of data from two 26-week, prospective clinical trials to investigate the effect of treating patients with moderate-to-severe dyspnea with the once-daily LABA/LAMA combination indacaterol/glycopyrronium (IND/GLY) $110 / 50 \mu \mathrm{g}$ compared with placebo, once-daily tiotropium $18 \mu \mathrm{g}$, and

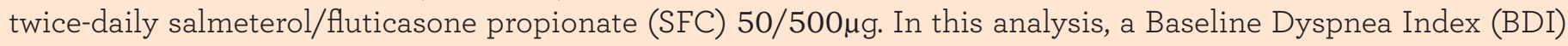
score $\leq 7$ was used to identify dyspneic patients.

Results: In dyspneic patients, IND/GLY significantly improved Transition Dyspnea Index (TDI) total scores compared with tiotropium (0.59 units; $p<0.05$ ) and SFC (0.97 units; $p<0.05)$, and significantly increased the likelihood of a patient achieving a 1-unit improvement in TDI compared with tiotropium (odds ratio [OR] 1.87; $p<0.05)$. IND/GLY also significantly improved trough forced expiratory volume in 1 second $\left(F E V_{1}\right)$ compared with tiotropium and SFC ( $p<0.001$ and $p<0.0001$, respectively), and significantly reduced rescue medication use compared with tiotropium $(p<0.001)$.

Conclusions: Our analysis indicates that IND/GLY provides additional improvements in dyspnea and lung function compared with tiotropium and SFC in dyspneic patients.

\footnotetext{
Abbreviations: Global initiative for chronic Obstructive Lung Disease, GOLD; chronic obstructive pulmonary disease, COPD; longacting beta2-agonist, LABA; long-acting muscarinic antagonist, LAMA; indacaterol/glycopyrronium, IND/GLY; salmeterol/fluticasone propionate, SFC; Baseline Dyspnea Index, BDI; Transition Dyspnea Index, TDI; odds ratio, OR; forced expiratory volume in 1 second, FEV $\mathbf{1}$; modified Medical Research Council, mMRC; inhaled corticosteroid, ICS; area under the curve from 0 to 12 hours, $\mathbf{A U C} \mathbf{C}_{\mathbf{0}} \mathbf{1 2 h}$; St. George's Respiratory Questionnaire, SGRQ; forced vital capacity, FVC; electronic diary, eDiary; confidence interval, CI; least squares, LS; standard error, SE; standard deviation, SD; least-squares mean, LSM

Funding Support: Medical writing support was funded by Novartis Pharma AG (Basel, Switzerland).

Date of Acceptance: July 14, 2016

Citation: Mahler DA, Keininger DL, Mezzi K, Fogel R, Banerji D. Efficacy of indacaterol/glycopyrronium in patients with COPD who have increased dyspnea with daily activities. Chronic Obstr Pulm Dis (Miami). 2016;3(4):758-768. doi: http://dx.doi.org/10.15326/ jcopdf.3.4.2016.0138
}

1 Professor Emeritus, Geisel School of Medicine at Dartmouth, Hanover, New Hampshire

3 Novartis Pharmaceuticals Corporation, East Hanover, New Jersey

2 Novartis Pharma AG, Basel, Switzerland 


\section{Address correspondence to:}

Donald A. Mahler, MD

Valley Regional Hospital

243 Elm Street

Claremont, $\mathrm{NH} 03743$

Tel: (603) 277-0383

Fax: (603) 542-6731

Email: mahlerdonald@gmail.com

\section{Keywords:}

Baseline Dyspnea Index; chronic obstructive pulmonary disease; COPD; dual bronchodilation; glycopyrronium; indacaterol; QVA149; Transition Dyspnea Index

\section{Introduction}

Chronic obstructive pulmonary disease (COPD) is a heterogeneous disease. ${ }^{1}$ Within individual categories of airflow limitation (Global initiative for chronic Obstructive Lung Disease [GOLD $]^{2}$ grades), high variability is observed in symptoms, health status, exercise capacity, and exacerbation frequency. ${ }^{1}$ In a factor-loading analysis of patients with (predominantly severe) COPD, variability in symptoms contributed more than any other variable in explaining disease heterogeneity. ${ }^{3}$ Therefore, patients with severe airflow limitation may not necessarily have a poor health status or a high symptom burden, and vice versa. ${ }^{1}$ Since studies indicate that only a modest correlation exists between airflow limitation, symptoms, and health status, ${ }^{4,5}$ GOLD suggests that post-bronchodilator forced expiratory volume in 1 second $\left(\mathrm{FEV}_{1}\right)$ alone is an incomplete descriptor of COPD disease status, and does not adequately capture disease heterogeneity. ${ }^{2}$ For this reason, GOLD recommends a combined assessment of symptom severity, airflow limitation, and/or exacerbation risk for the effective evaluation of disease status in patients with COPD. ${ }^{2}$

Dyspnea is a principal symptom of COPD and a major cause of disability. ${ }^{2}$ Dyspnea severity can be measured using a range of tools in addition to the modified Medical Research Council (mMRC) questionnaire recommended by GOLD for the assessment of symptoms. The Baseline Dyspnea Index (BDI) and the Transition Dyspnea Index (TDI) are widely used for the measurement of dyspnea in clinical trials. ${ }^{6}$ The BDI and TDI provide multidimensional, interview-based measurements of breathlessness based on activities of daily living through the assessment of 3 components that provoke breathing difficulty: functional impairment, magnitude of task, and magnitude of effort. ${ }^{7,8}$ To establish baseline dyspnea severity using the BDI, each of the 3 components is assessed and scored on a scale from 0 (severe) to 4 (unimpaired), with the total BDI score out of 12 obtained through adding together the scores for each component. ${ }^{7}$ A lower BDI score therefore indicates a higher severity of dyspnea at baseline. ${ }^{7}$

BDI score correlates well with $\mathrm{mMRC}$ grade and other measures of dyspnea in patients with COPD, 8,9 as well as with exercise capacity, ${ }^{7,10}$ quality of life, ${ }^{11}$ and mortality. ${ }^{12}$ However, BDI scores correlate only modestly (but significantly) with lung function. ${ }^{7}$ Several comparisons of different dyspnea scales have indicated that the BDI has the highest levels of reliability and validity. ${ }^{9,13}$

The recommended treatment for patients with mildto-moderate COPD who are experiencing dyspnea is monotherapy with a long-acting beta2-agonist (LABA) or long-acting muscarinic antagonist (LAMA). ${ }^{2}$ If the patient continues to experience dyspnea, or if dyspnea is severe, GOLD recommends the use of LABAs and LAMAs in combination. ${ }^{2}$

The purpose of this post-hoc analysis was to investigate the efficacy of fixed-dose LABA/LAMA combination QVA149 (indacaterol/glycopyrronium

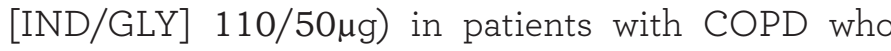
experienced moderate-to-severe dyspnea at baseline. Dyspneic patients were identified based on a BDI score $\leq 7$. We primarily studied the patient-reported outcomes dyspnea and health status, with supportive analysis of lung function and rescue medication use.

Our aim was to confirm the efficacy of a LABA/LAMA in the treatment of dyspneic patients, as recommended in the GOLD treatment strategy, in comparison with commonly prescribed LAMA monotherapy tiotropium and LABA/inhaled corticosteroid (ICS) salmeterol/ fluticasone propionate (SFC).

\section{Methods}

\section{Study Design}

This post-hoc analysis was conducted using data from 2 pivotal IND/GLY clinical studies, SHINE $^{14}$ and ILLUMINATE. ${ }^{15}$ These studies were selected based on similarities in duration (26 weeks), endpoints studied (the primary endpoint in both studies was lung function), and patient population (both studies enrolled symptomatic patients with moderate-to-severe COPD; the majority of patients in both studies had moderate COPD). The studies were not combined for the analysis, 
but analyzed separately.

Full details of SHINE and ILLUMINATE have been published previously. ${ }^{14,15}$ Briefly, SHINE (NCT01202188) was a 26-week, randomized,

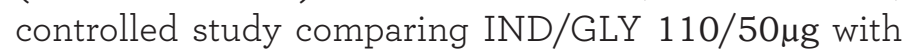

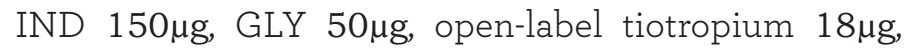
and placebo, all administered once daily. ILLUMINATE (NCT01315249) was a 26-week, randomized study comparing once-daily IND/GLY $110 / 50 \mu$ g with twicedaily SFC 50/500 $\mu$ g, both administered double-blind.

The primary endpoints in SHINE and ILLUMINATE were trough FEV 1 for IND/GLY compared with IND and GLY, and FEV 1 area under the curve from 0 to 12 hours (FEV 1 AUC $0-12 \mathrm{~h}$ ) for IND/GLY compared with SFC, respectively (both at 26 weeks). Secondary endpoints in both studies included TDI total score, daily rescue medication use, and St. George's Respiratory Questionnaire (SGRQ) total score. Safety and tolerability were also assessed in both studies. In this post-hoc analysis, we studied the treatment differences with IND/GLY compared with placebo and established treatments tiotropium and SFC in patients with COPD who experience moderate-to-severe dyspnea at baseline. We focused on dyspnea and health status, with supportive analysis of lung function and rescue medication use. Exacerbations were not investigated as the studies analyzed were not optimized to determine meaningful changes in exacerbation rate.

\section{Patients}

SHINE and ILLUMINATE enrolled men and women aged $\geq 40$ years, with a diagnosis of moderate-tosevere COPD (Stage II or III according to GOLD 2008 criteria), and with a smoking history of $\geq 10$ pack years. At screening, patients were required to have a postbronchodilator $\mathrm{FEV}_{1} \geq 30 \%$ and $<80 \%$ of the predicted normal value in SHINE, and a post-bronchodilator $\mathrm{FEV}_{1} \geq 40 \%$ and $<80 \%$ of the predicted normal value in ILLUMINATE. Patients enrolled in both studies had a post-bronchodilator $\mathrm{FEV}_{1}$ /forced vital capacity (FVC) ratio $<70 \%$. Patients were required to be symptomatic at baseline in both studies, assessed using a patientcompleted daily electronic diary (eDiary). Symptoms were recorded during a 14-day run-in period and were measured on a scale of 0 to 3 (where 0 refers to no symptoms). Patients with a total symptom score $\geq 1$ on 4 or more of the last 7 days prior to Visit 3 (Day 1) were classified as symptomatic. Patients with a COPD exacerbation requiring treatment with antibiotics, systemic corticosteroids or hospitalization were excluded from SHINE if the exacerbation occurred during the 6 weeks prior to the study, and from ILLUMINATE if the exacerbation occurred within 1 year prior to the study. Patients with a respiratory tract infection within the 4 weeks prior to Visit 1 were excluded from both studies. Concomitant ICS use (in constant doses and dose regimens for at least 1 month) was permitted in SHINE, but not in ILLUMINATE. Patients were provided with a salbutamol inhaler for use as rescue medication during both studies.

\section{Assessments and Variables}

In SHINE and ILLUMINATE, dyspnea was measured using the BDI at baseline and the TDI at Weeks 12 and 26. Health status was measured using the SGRQ at baseline and at Weeks 12 and 26 in both studies. In SHINE, FEV 1 was assessed at baseline, Days 1 and 2, and Weeks 2, 4, 8, 12, 16, 20, and 26. In ILLUMINATE, $\mathrm{FEV}_{1}$ was assessed at baseline, Day 1, and Weeks 6, 12, 18 , and 26 . Use of rescue medication in the 2 studies was measured over the 26-week treatment period using an eDiary.

\section{BDI Stratification}

Studies suggest that a BDI score $\leq 7$ correlates with an mMRC grade $\geq 2$, the GOLD cut-off for symptomatic patients. ${ }^{2,9,10,16}$ Patients with a BDI score $\leq 7$ were therefore selected as a subgroup to represent patients with moderate-to-very severe dyspnea. Patients with a BDI score $\leq 7$ have moderate-to-very severe functional impairment and experience shortness of breath when exerting moderate-to-no effort and when carrying out few tasks. ${ }^{7}$ Data from the wider stratifications of a BDI score $\leq 6$ and $\leq 8$ were also analyzed, to provide further information on the efficacy of IND/GLY in patients who had severe dyspnea at baseline.

\section{Statistical Analysis}

Statistical analyses were performed using SAS statistical software version 9.3 (SAS Institute, Cary, North Carolina). Main demographic parameters were analyzed by means of descriptive statistics. TDI, change in trough $\mathrm{FEV}_{1}$, mean rescue medication use (puffs/day), and SGRQ total score were assessed by means of a mixed model with treatment, baseline $\mathrm{FEV}_{1}, \mathrm{FEV}_{1}$ reversibility components, baseline smoking status, baseline ICS use, region, and center (region) as covariates. The differences in the proportion of patients with a 1-unit 
improvement in TDI total score ${ }^{17}$ and the proportion of patients with a 4-unit improvement in SGRQ total score ${ }^{18}$ were assessed via logistic regression, using the same covariates as for the other efficacy variables. For this post-hoc analysis, last observation carried forward values at 26 weeks were used.

\section{Results}

\section{Patients}

Distribution of BDI scores in SHINE and ILLUMINATE indicate that most patients were at least moderately symptomatic based on BDI score (Figure 1).

Patient baseline demographics and characteristics of the total study populations and BDI $\leq 7$ subgroups are displayed in Table 1. Seventy-five percent of patients in the total SHINE population and $71 \%$ of patients in the total ILLUMINATE population had a BDI score $\leq 7$. The total study populations and BDI $\leq 7$ subgroups were similar in terms of age, sex, and smoking status. A slightly higher proportion of patients in the BDI $\leq 7$ subgroup had severe COPD compared with the total population for both SHINE (41.4\% and 36.3\%, respectively) and ILLUMINATE (24.0\% and 19.7\%, respectively). Mean post-bronchodilator $\mathrm{FEV}_{1}$ was similar between the total population and the BDI $\leq 7$ subgroup for both SHINE (55.2\% and 53.6\%, respectively) and ILLUMINATE
(60.2\% and $58.7 \%$, respectively).

Approximately half of the patients in both SHINE and ILLUMINATE had a BDI score $\leq 6$, and $84 \%$ of patients in SHINE and $81 \%$ of patients in ILLUMINATE had a BDI score $\leq 8$.

\section{Efficacy in the BDI $\leq 7$ Subgroups}

\section{Dyspnea}

\section{TDI Total Score}

IND/GLY significantly improved dyspnea compared with placebo, tiotropium, and SFC, with treatment differences of 1.13 units ( $p<0.001), 0.59$ units $(p<0.05)$, and 0.97 units $(p<0.05)$, respectively (Figure 2 and Table 2 ).

\section{TDI Responders}

IND/GLY significantly increased the proportion of patients achieving a 1-unit improvement in TDI total score compared with placebo (odds ratio [OR] 2.25; 95\% confidence interval [CI] 1.33, $3.80[p<0.05])$ and tiotropium (OR 1.87; 95\% CI 1.23, 2.84 [p<0.05]) (Figure 3 and Table 2). There was a non-significant, numerical difference in the proportion of patients achieving a 1-unit improvement in TDI total score with IND/GLY compared with SFC (OR 1.46; 95\% CI 0.91, $2.35[p=0.117])$.

\section{Figure 1. Distribution of Patients at Baseline in the SHINE and ILLUMINATE Studies by BDI Score}
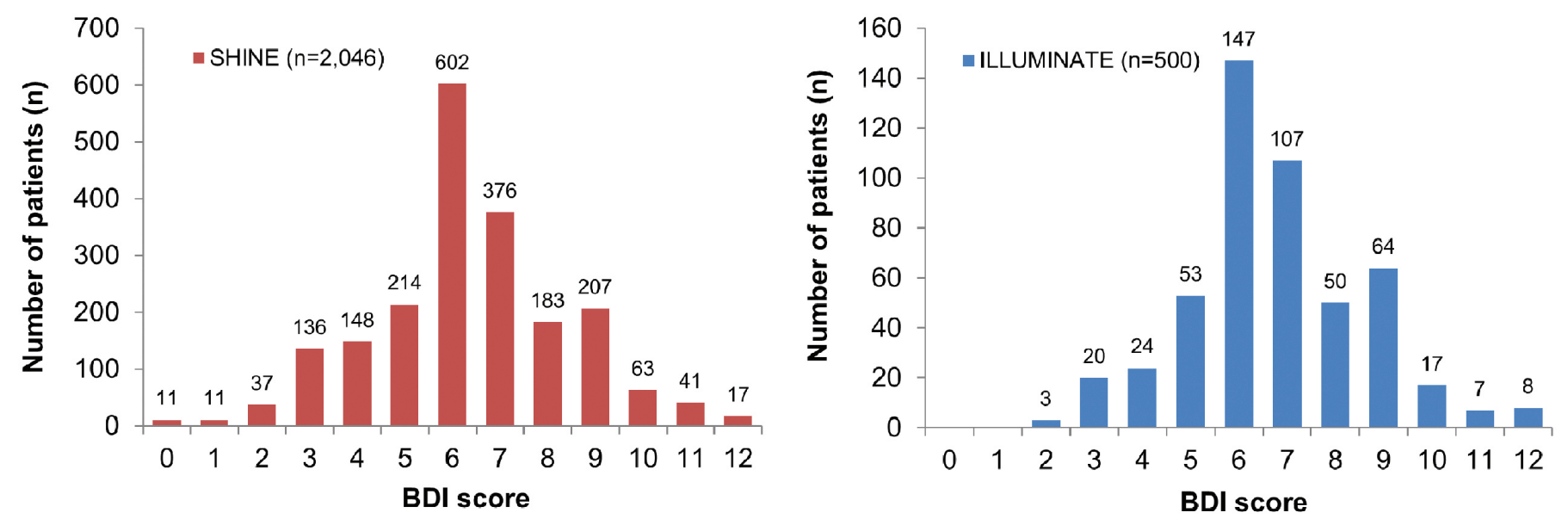

\begin{tabular}{rrrrrrrrrrrrrrr} 
& BDI score & 0 & 1 & 2 & 3 & 4 & 5 & 6 & 7 & 8 & 9 & 10 & 11 & 12 \\
Cumulative & SHINE & $1 \%$ & $1 \%$ & $3 \%$ & $10 \%$ & $17 \%$ & $27 \%$ & $57 \%$ & $75 \%$ & $84 \%$ & $94 \%$ & $97 \%$ & $99 \%$ & $100 \%$ \\
$\%$ of patients & ILLUMINATE & $0 \%$ & $0 \%$ & $1 \%$ & $5 \%$ & $9 \%$ & $20 \%$ & $49 \%$ & $71 \%$ & $81 \%$ & $94 \%$ & $97 \%$ & $98 \%$ & $100 \%$ \\
\hline
\end{tabular}

BDI=Baseline Dyspnea Index 


\section{Table 1. Demographics and Baseline Characteristics of the Total Study Population and BDI $\leq 7$ Subgroups in the SHINE and ILLUMINATE Studies}

\begin{tabular}{|c|c|c|c|c|}
\hline & \multicolumn{2}{|c|}{ SHINE14 } & \multicolumn{2}{|c|}{ ILLUMINATE15 } \\
\hline & $\begin{array}{c}\text { Total } \\
\text { Population }\end{array}$ & $\mathrm{BDI} \leq 7$ & $\begin{array}{c}\text { Total } \\
\text { Population }\end{array}$ & $\mathrm{BDI} \leq 7$ \\
\hline Participants, $\mathbf{n}$ & 2135 & 1535 & 522 & 354 \\
\hline \multicolumn{5}{|l|}{ Age, $\mathbf{n}(\%)$} \\
\hline$<65$ years & $1104(51.7)$ & $801(52.2)$ & 295 (56.5) & $205(57.9)$ \\
\hline $65 \leq 75$ years & 757 (35.5) & $533(34.7)$ & $187(35.8)$ & $121(34.2)$ \\
\hline$\geq 75$ years & $274(12.8)$ & $201(13.1)$ & $40(7.7)$ & $28(7.9)$ \\
\hline Male, $\mathbf{n}(\%)$ & $1610(75.4)$ & $1136(74.0)$ & $370(70.9)$ & $251(70.9)$ \\
\hline \multicolumn{5}{|l|}{ COPD Severity, n (\%) } \\
\hline Moderate & 1358 (63.6) & 899 (58.6) & $419(80.3)$ & $269(76.0)$ \\
\hline Severe & 775 (36.3) & $635(41.4)$ & $103(19.7)$ & $85(24.0)$ \\
\hline ICS Use, $\mathbf{n}(\%)$ & $1227(57.5)$ & $939(61.2)$ & $183(35.1)$ & $125(35.3)$ \\
\hline \multicolumn{5}{|l|}{ Smoking Status, n (\%) } \\
\hline Ex-smoker & $1288(60.3)$ & $932(60.7)$ & $272(52.1)$ & $186(52.5)$ \\
\hline Current Smoker & $847(39.7)$ & $603(39.3)$ & $250(47.9)$ & $168(47.5)$ \\
\hline \multicolumn{5}{|l|}{ COPD Exacerbation History, $n$ (\%) } \\
\hline $\mathbf{0}$ & $1593(74.6)$ & $1111(72.4)$ & $521(99.8)$ & $353(>99.0)$ \\
\hline 1 & $421(19.7)$ & $321(20.9)$ & $1(0.2)$ & $1(<1.0)$ \\
\hline$\geq 2$ & $121(5.7)$ & $103(6.7)$ & 0 & 0 \\
\hline Pre-bronchodilator FEV 1 \% Predicted, mean (SD) & $46.9(13.4)$ & $45.4(13.2)$ & $50.9(11.5)$ & $49.5(11.6)$ \\
\hline Post-bronchodilator $\mathrm{FEV}_{1} \%$ Predicted, mean (SD) & $55.2(13.2)$ & $53.6(13.0)$ & $60.2(10.6)$ & $58.7(10.7)$ \\
\hline Post-bronchodilator FEV 1 Reversibility, mean (SD) & $20.3(17.0)$ & $20.5(17.3)$ & $20.4(14.2)$ & $20.9(14.0)$ \\
\hline
\end{tabular}

$\mathrm{BDI}=$ Baseline Dyspnea Index; $\mathrm{COPD}=$ chronic obstructive pulmonary disease; $\mathrm{FEV}_{1}=$ forced expiratory volume in 1 second; ICS=inhaled corticosteroid; $\mathrm{SD}=$ standard deviation

\section{Health Status}

\section{SGRQ Total Score}

IND/GLY significantly improved SGRQ total score compared with placebo, with a treatment difference of -2.57 units $(p<0.05$; Figure 4 and Table 2$)$. There was a non-significant, numerical difference in SGRQ total score between IND/GLY and tiotropium (treatment difference: -1.55 units $[p=0.117])$ and IND/GLY and SFC (treatment difference: $-1.06[p=0.414])$.

\section{SGRQ Responders}

There was no significant difference in the proportion of patients achieving a 4-unit improvement in SGRQ total score with IND/GLY compared with placebo (OR 1.20; 95\% CI 0.76, 1.89 [ $p=0.425]$ ), tiotropium (OR 1.11; 95\% CI $0.78,1.58[p=0.570])$ or SFC (OR 1.30; 95\% CI 0.08, $22.51[p=0.451]$ ) (Figure 5 and Table 2).

\section{Lung Function}

IND/GLY significantly improved trough $\mathrm{FEV}_{1}$ compared with placebo, tiotropium, and SFC, with treatment differences of 0.19L ( $p<0.0001), 0.06 \mathrm{~L}(p<0.001)$, and $0.10 \mathrm{~L}(p<0.0001)$, respectively (Figure 6 and Table 2 ).

\section{Rescue Medication Use}

IND/GLY significantly improved rescue medication use compared with placebo and tiotropium, with treatment differences of -0.92 puffs/day $(p<0.0001)$ and -0.59 puffs/day $(p<0.001)$, respectively (Figure 7 and Table 2). There was a non-significant, numerical difference in rescue medication use between IND/GLY and SFC (treatment difference: -0.24 puffs/day [ $p=0.235]$ ).

\section{Efficacy in the $B D I \leq 6$ and $B D I \leq 8$ Subgroups}

The results for the BDI $\leq 6$ and BDI $\leq 8$ stratifications 


\section{Figure 2. Mean Treatment Difference in TDI Total Score at Week 26 in Patients with a BDI Score $\leq 7$}

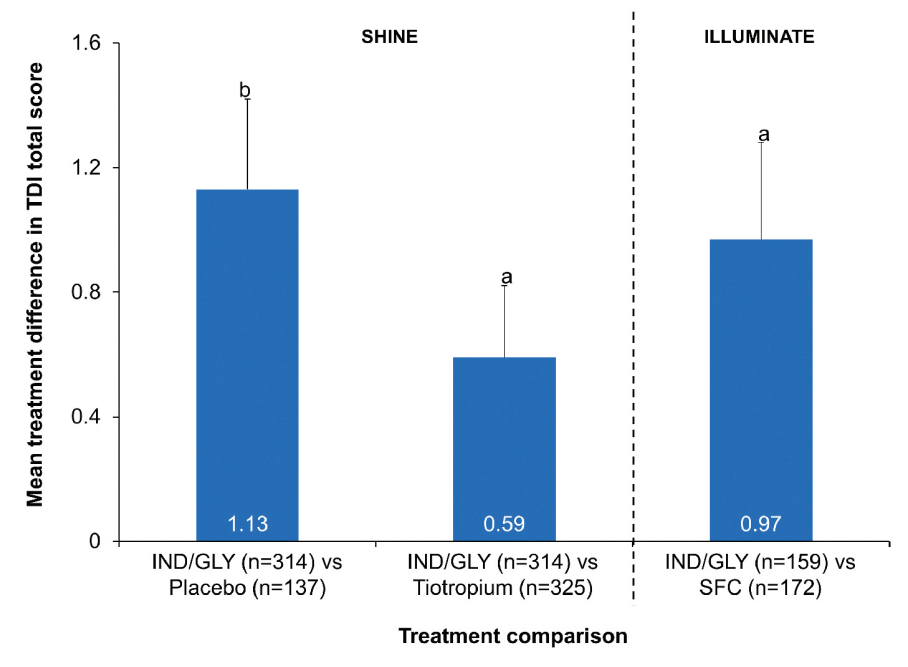

Data are LS mean (SE).

$\mathrm{a}=p<0.05 ; \mathrm{b}=p<0.001$ for IND/GLY versus comparator BDI=Baseline Dyspnea Index; IND/GLY=indacaterol/

glycopyrronium fixed-dose combination; $\mathrm{LS}=$ least squares; $\mathrm{SE}=$ standard error; SFC=salmeterol/fluticasone propionate combination;

TDI=Transition Dyspnea Index

were largely similar to those for the BDI $\leq 7$ subgroups, for all endpoints studied (Table 2). However, the BDI $\leq 7$ subgroup demonstrated the biggest effects in TDI score, proportional with TDI improvement and trough $\mathrm{FEV}_{1}$.

\section{Discussion}

This post-hoc analysis indicates the relative efficacy of IND/GLY compared with placebo, tiotropium, and SFC in patients with moderate-to-severe dyspnea at baseline, based on a BDI score $\leq 7$. According to the BDI questionnaire, patients with a BDI score $\leq 7$ have moderate-to-very severe functional impairment and experience shortness of breath with moderate-to-no effort and when carrying out moderate-to-no tasks at all. ${ }^{7}$ In these patients, symptoms can affect ability to work and carry out normal activities. ${ }^{7}$

In dyspneic patients with mild-to-moderate airflow limitation and no exacerbation history (GOLD Group B), monotherapy with a long-acting bronchodilator provides significant improvements in dyspnea, lung function, and rescue medication use compared with placebo. ${ }^{19}$ However, some patients continue to experience dyspnea despite receiving bronchodilator monotherapy. ${ }^{20,21}$ According to GOLD, a combination of long-acting bronchodilators may be considered if symptoms such as dyspnea are not improved with monotherapy. ${ }^{2}$ Although analyses based on severity of airflow limitation were not performed, the majority of dyspneic patients in our analysis had moderate airflow limitation and no exacerbation history, and would therefore be categorized as GOLD Group B.

Our post-hoc analysis indicates that the LABA/ LAMA combination IND/GLY was more effective than tiotropium monotherapy at improving dyspnea, lung function, and rescue medication use in dyspneic patients with COPD. The findings support the results of the 6-week BLAZE cross-over study, which demonstrated that IND/GLY significantly improved dyspnea, lung function, and rescue medication use compared with placebo and tiotropium in dyspneic patients (patients with an $\mathrm{mMRC}$ grade $\geq 2$ at screening). ${ }^{22}$

Post-hoc analysis of the TORCH study indicates that pharmacotherapy is most effective in patients with milder disease, compared with placebo. ${ }^{23} \mathrm{~A}$ considerable amount of data from clinical trials demonstrates that LABA/LAMAs as a class provide benefits beyond placebo and long-acting bronchodilator monotherapy with regard to lung function and patientreported outcomes. ${ }^{14,24-29}$ In addition, IND/GLY has demonstrated significant improvements in lung function compared with placebo, independent of prior medication. ${ }^{30}$ We therefore suggest that the use of LABA/LAMA combinations be considered earlier in the course of disease, or even as first-line therapy.

LABA/ICS combinations are not recommended for use in patients in GOLD Group B, as the risks associated with ICS appear to outweigh the benefits of such treatment in patients at low risk of exacerbation. ${ }^{2}$ However, ICS use in GOLD Group B patients is widespread. ${ }^{20,31-36}$ In the dyspneic patients studied in our analysis, IND/GLY was significantly better than SFC at improving dyspnea and lung function, providing supportive evidence for the efficacy of a dual bronchodilator compared with a LABA/ICS in the treatment of GOLD Group B patients. 


\section{Table 2. Treatment Differences with IND/GLY Versus Placebo, Tiotropium, and SFC in Patients Stratified by Baseline Dyspnea Severity}

\begin{tabular}{|c|c|c|c|}
\hline & & Patient Subgrou & \\
\hline & $\mathrm{BDI} \leq 6$ & $\mathrm{BDI} \leq 7$ & $\mathrm{BDI} \leq 8$ \\
\hline TDI Total Score, units $195 \%$ & & & \\
\hline IND/GLY vs. Placebo & $1.07^{\mathrm{a}}(0.39,1.74)$ & $1.13^{b}(0.54,1.72)$ & $1.07^{\mathrm{b}}(0.52,1.63)$ \\
\hline IND/GLY vs. Tiotropium & $0.45(-0.08,0.97)$ & $0.59^{\mathrm{a}}(0.14,1.05)$ & $0.50^{\mathrm{a}}(0.08,0.93)$ \\
\hline IND/GLY vs. SFC & $0.53(-0.22,1.29)$ & $0.97^{\mathrm{a}}(0.35,1.58)$ & $0.86^{\mathrm{a}}(0.31,1.42)$ \\
\hline Proportion of Patients Achi & ovement in TDI Tot & Score, odds ratio $(95 \%$ & CI) \\
\hline IND/GLY vs. Placebo & $2.07^{\mathrm{a}}(1.13,3.78)$ & $2.25^{a}(1.33,3.80)$ & $2.15^{\mathrm{a}}(1.32,3.50)$ \\
\hline IND/GLY vs. Tiotropium & $2.01^{\mathrm{a}}(1.23,3.27)$ & $1.87^{\mathrm{a}}(1.23,2.84)$ & $1.75^{\mathrm{a}}(1.20,2.57)$ \\
\hline IND/GLY vs. SFC & $1.04(0.59,1.83)$ & $1.46(0.91,2.35)$ & $1.46(0.93,2.29)$ \\
\hline SGRQ Total Score, units $(95$ & & & \\
\hline IND/GLY vs. Placebo & $-2.23(-5.17,0.71)$ & $-2.57^{a}(-5.08,-0.06)$ & $-2.55^{\mathrm{a}}(-4.90,-0.19)$ \\
\hline IND/GLY vs. Tiotropium & $-0.90(-3.20,1.39)$ & $-1.55(-3.50,0.39)$ & $-2.09^{\mathrm{a}}(-3.90,-0.28)$ \\
\hline IND/GLY vs. SFC & $0.17(-3.04,3.37)$ & $-1.06(-3.61,1.49)$ & $-0.86(-3.16,1.43)$ \\
\hline Proportion of Patients Achi & ovement in SGRQ T & al Score, odds ratio ( 9 & $\%$ CI) \\
\hline IND/GLY vs. Placebo & $1.23(0.73,2.09)$ & $1.20(0.76,1.89)$ & $1.15(0.76,1.76)$ \\
\hline IND/GLY vs. Tiotropium & $0.96(0.63,1.46)$ & $1.11(0.78,1.58)$ & $1.21(0.88,1.68)$ \\
\hline IND/GLY vs. SFC & $1.09(0.03,33.81)$ & $1.30(0.08,22.51)$ & $1.28(0.09,18.13)$ \\
\hline Trough FEV $_{1}, \mathrm{~L}(95 \% \mathrm{CI})$ & & & \\
\hline IND/GLY vs. Placebo & $0.17^{\mathrm{c}}(0.12,0.22)$ & $0.19^{c}(0.14,0.23)$ & $0.19^{\mathrm{c}}(0.15,0.23)$ \\
\hline IND/GLY vs. Tiotropium & $0.06^{\mathrm{a}}(0.02,0.10)$ & $0.06^{b}(0.03,0.09)$ & $0.06^{\mathrm{b}}(0.03,0.09)$ \\
\hline IND/GLY vs. SFC & $0.08^{\mathrm{a}}(0.02,0.14)$ & $0.10^{c}(0.06,0.15)$ & $0.09^{\mathrm{c}}(0.05,0.14)$ \\
\hline Rescue Medication Use, puf & & & \\
\hline IND/GLY vs. Placebo & $-0.86^{\mathrm{a}}(-1.39,-0.32)$ & $-0.92^{\mathrm{c}}(-1.37,-0.48)$ & $-0.95^{\mathrm{c}}(-1.37,-0.54)$ \\
\hline IND/GLY vs. Tiotropium & $-0.60^{\mathrm{a}}(-1.03,-0.18)$ & $-0.59^{b}(-0.95,-0.24)$ & $-0.54^{\mathrm{a}}(-0.87,-0.22)$ \\
\hline IND/GLY vs. SFC & $-0.24(-0.73,0.25)$ & $-0.24(-0.65,0.16)$ & $-0.32(-0.69,0.05)$ \\
\hline
\end{tabular}

${ }^{\mathrm{a}}{ }_{p<0.05}{ }^{\mathrm{b}}{ }_{p<0.001 ;}{ }^{\mathrm{c}} p<0.0001$ for IND/GLY versus comparator. Treatment differences are LSM (95\% CI), with the exception of odds ratios $\mathrm{BDI}=$ Baseline Dyspnea Index; $\mathrm{CI}=$ confidence interval; $\mathrm{FEV}_{1}=$ forced expiratory volume in 1 second; IND/GLY=indacaterol/glycopyrronium fixed-dose combination; LSM=least-squares mean; SFC=salmeterol/fluticasone propionate combination; SGRQ=St. George's Respiratory Questionnaire; TDI=Transition Dyspnea Index

Analysis of patients with a BDI score $\leq 6$ and $\leq 8$ indicates that the relative efficacy of IND/GLY is largely consistent in patients with slightly worse or slightly milder dyspnea, respectively. However, the largest improvement in TDI was seen in the $\leq 7$ subgroup. This possibly could be attributed to decreased room for improvement in the $\leq 8$ group, and the $\leq 6$ group being a smaller subgroup of patients.

The magnitude of response in terms of dyspnea improvement was slightly larger in the BDI $\leq 7$ subgroups compared with the total study populations. ${ }^{14,15}$ The improvement in TDI total score observed with IND/ GLY compared with SFC in the BDI $\leq 7$ subgroup was 0.97 units; in the total ILLUMINATE population, improvement in TDI total score was 0.76 units. $^{15}$ In addition, improvement in TDI total score observed with IND/GLY compared with tiotropium in the BDI $\leq 7$ subgroup was 0.59 units; in the total SHINE population, improvement in TDI total score was 0.51 units. ${ }^{14}$ Of interest, more patients in the BDI $\leq 7$ subgroups had severe COPD compared with the total populations. In BLAZE, the magnitude of response in terms of dyspnea improvement was greater in patients with severe COPD than those with moderate COPD. ${ }^{22}$

Previous analyses have indicated that pharmacotherapy may be less effective in patients with severe-to-very severe COPD than in patients with milder COPD in terms of lung function improvements. ${ }^{23}$ If lung function improvements correlate with improvements in dyspnea, then it might be expected that pharmacotherapy would be less effective at improving dyspnea in patients with more severe 


\section{Figure 3. Proportion of Patients with |Figure 5. Proportion of Patients with a 1-unit Improvement in TDI in Patients with a BDI Score $\leq 7$ 4-unit Improvement in SGRQ Score in Patients with a BDI Score $\leq 7$}

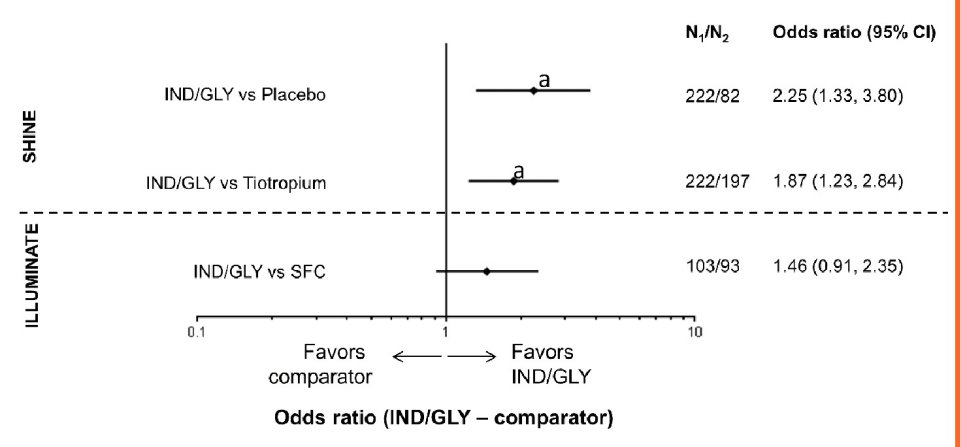

$a=p<0.05$ for IND/GLY versus comparator

$\mathrm{BDI}=$ Baseline Dyspnea Index; $\mathrm{CI}=$ confidence interval; IND/GLY=indacaterol/ glycopyrronium fixed-dose combination; $\mathrm{N}_{1}=$ number of patients included in the analysis in the IND/GLY arm of the respective subgroup; $\mathrm{N}_{2}=$ number of patients included in the analysis in the comparator arm of the respective subgroup; $\mathrm{SFC}=$ salmeterol/fluticasone propionate combination;

TDI=Transition Dyspnea Index

\section{Figure 4. SGRQ Change from Baseline at Week 26 in Patients with a BDI Score $\leq 7$}

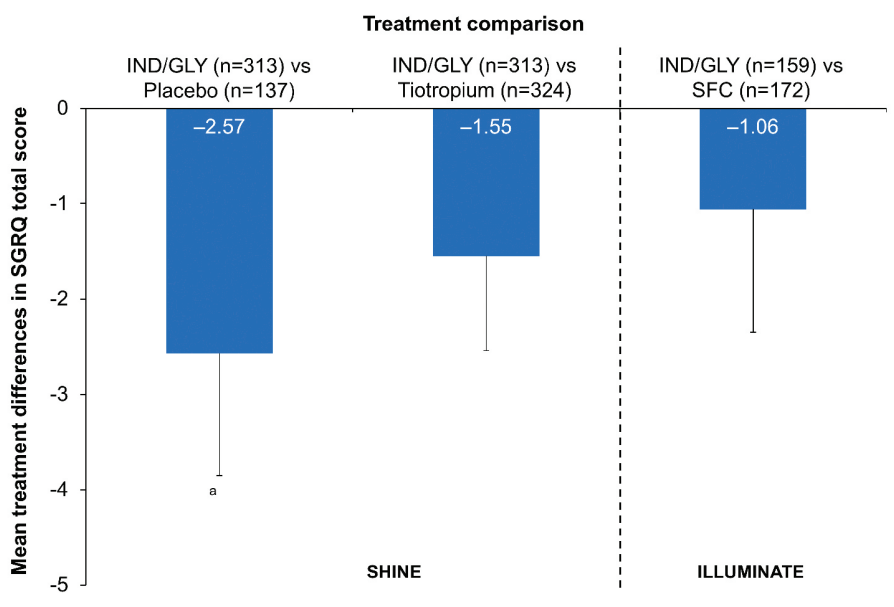

Data are LS mean (SE). $\mathrm{a}=p<0.05$ for IND/GLY versus comparator $\mathrm{BDI}=$ Baseline Dyspnea Index; IND/GLY=indacaterol/glycopyrronium fixed-dose combination; $\mathrm{SFC}=$ salmeterol/fluticasone propionate combination; SGRQ=St. George's Respiratory Questionnaire

disease, which is inconsistent with our findings. The correlation between lung function and symptoms has previously been identified as modest. ${ }^{4,5}$ Our findings may support the need for composite endpoints to more fully assess treatment efficacy in patients with COPD. ${ }^{37}$

In our analysis, the majority of the improvements observed with IND/GLY compared with tiotropium and SFC did not reach commonly accepted minimal

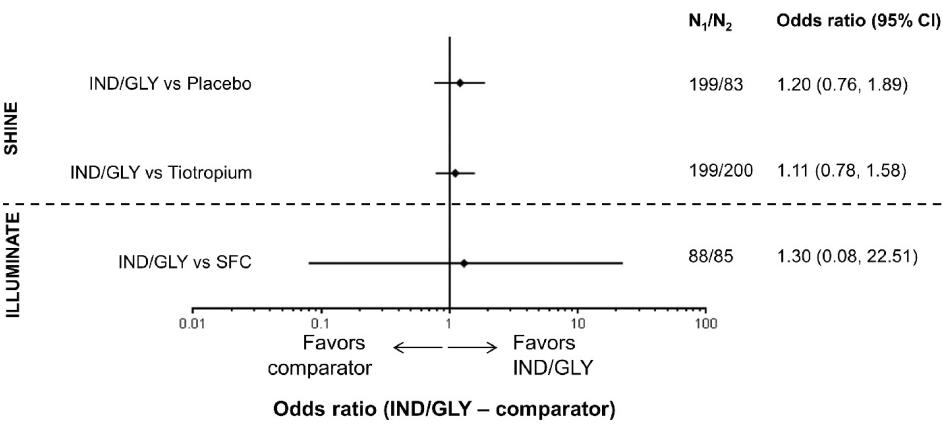

BDI=Baseline Dyspnea Index; CI=confidence interval; IND/GLY=indacaterol/ glycopyrronium fixed-dose combination; $\mathrm{N}_{1}=$ number of patients included in the analysis in the IND/GLY arm of the respective subgroup; $\mathrm{N}_{2}=$ number of patients included in the analysis in the comparator arm of the respective subgroup; $\mathrm{SFC}=$ salmeterol/fluticasone propionate combination;

$\mathrm{SGRQ}=$ St. George's Respiratory Questionnaire

\section{Figure 6. Mean Treatment Difference in Trough $\mathrm{FEV}_{1}$ at Week 26 in Patients with a BDI Score $\leq 7$}

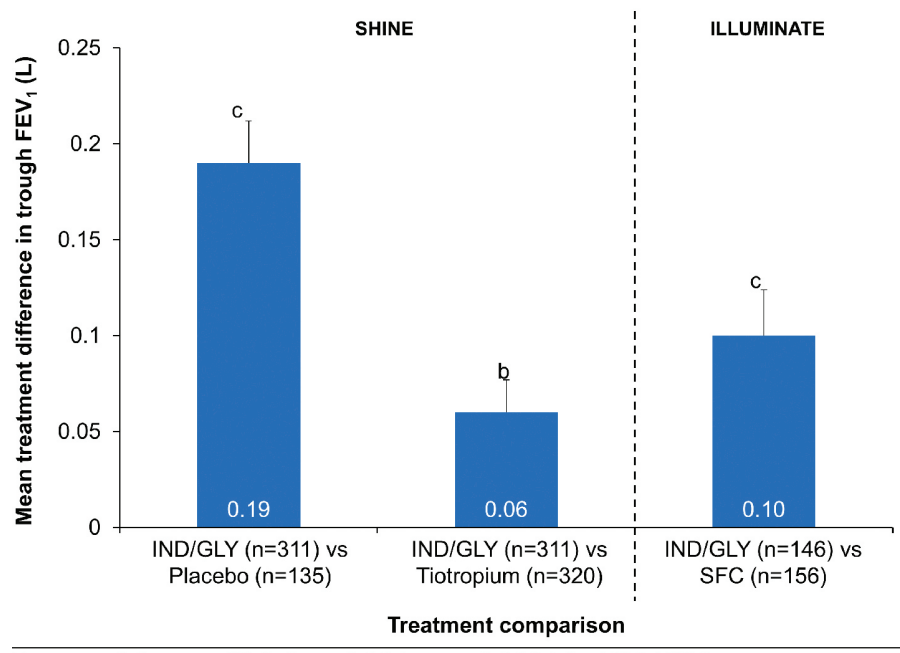

Data are LS mean (SE). $\mathrm{b}=p<0.001 ; \mathrm{c}=p<0.0001$ for IND / GLY versus comparator

$\mathrm{BDI}=$ Baseline Dyspnea Index; $\mathrm{FEV}_{1}$ =forced expiratory volume in 1 second; IND/GLY=indacaterol/glycopyrronium fixed-dose combination; LS=least squares; $\mathrm{SE}=$ standard error; $\mathrm{SFC}=$ salmeterol/fluticasone propionate combination

clinically important differences. However, it may be argued that it is not realistic for comparisons between active treatments to achieve MCID values determined using data versus placebo. ${ }^{38}$ Instead, responder analyses may be a more appropriate measure of a clinically relevant improvement when comparing active treatments, or when adding one treatment to another. ${ }^{38}$ The proposed term for this parameter is "minimum 


\section{Figure 7. Mean Treatment Difference in Change from Baseline Mean Daily Number of Puffs of Rescue Medication in Patients with a BDI Score $\leq 7$ Over 26 Weeks}

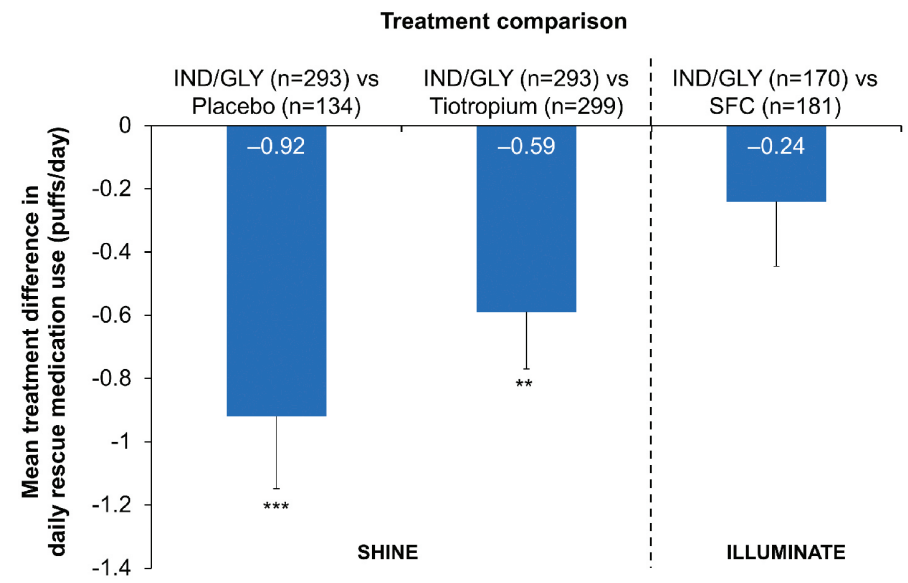

Data are LS mean (SE). $\mathrm{b}=p<0.001 ; \mathrm{c}=p<0.0001$ for IND/GLY versus comparator $\mathrm{BDI}=$ Baseline Dyspnea Index; IND/GLY=indacaterol/glycopyrronium fixed-dose combination; LS=least squares; $\mathrm{SE}=$ standard error; $\mathrm{SFC}=$ salmeterol/fluticasone propionate combination

worthwhile incremental advantage."38

It is important to note that there were some limitations in the present post-hoc analysis. A similar analysis has already been carried out on the whole population; however, this post-hoc analysis adds to the field as it specifically analyzes patients with dyspnea. GOLD recommends LABA/LAMA as an alternative to monotherapy in patients with mild-to-moderate airflow limitation and symptoms. ${ }^{2}$ Subgroup analyses can result in small patient numbers in certain subgroups. For instance, there were fewer than 200 patients in the IND/GLY and SFC treatment arms in the BDI $\leq 7$ subgroup in ILLUMINATE. Therefore, there may be a lack of power in these subgroups to detect differences, and the results should be interpreted with caution. In addition, subgroup analyses based on severity of airflow limitation were not conducted and therefore the patient populations do not model exactly to the GOLD classifications, which may limit the conclusions that may be drawn.

\section{Conclusion}

Our analysis indicated that IND/GLY provides significant benefits compared with tiotropium monotherapy in patients with COPD who are experiencing dyspnea. These data raise the consideration of using a LABA/LAMA combination earlier in the treatment algorithm, and even possibly as first-line therapy, in symptomatic patients categorized as GOLD Group B. Our analysis also indicated that IND/GLY was at least as effective as SFC in improving dyspnea and lung function, in a patient population in whom ICS use is not recommended due to the limited benefits and associated risks.

\section{Acknowledgments}

The authors were assisted in the preparation of the manuscript by Elizabeth Andrew, a professional medical writer at CircleScience, an Ashfield Company, part of UDG Healthcare plc (Tytherington, United Kingdom). Medical writing support was funded by Novartis Pharma AG (Basel, Switzerland).

\section{Declaration of Interest}

Donald Mahler has received consulting fees for advisory boards from Boehringer Ingelheim, GlaxoSmithKline, Novartis, Sunovion, and Theravance. He receives royalties from CRC Press, from Hillcrest Media Group Inc, and from MAPI Research Trust. He is on speakers' bureaus for Boehringer Ingelheim, GlaxoSmithKline, and Sunovion. His website (http://www.donaldmahler. $\mathrm{com}$ ) is an educational website for those with COPD and their families. Dorothy Keininger, Karen Mezzi, Robert Fogel, and Donald Banerji are full-time employees of Novartis. Robert Fogel and Donald Banerji own stock in Novartis. 


\section{References}

1. Agusti A, Calverley PM, Celli B, et al. Characterisation of COPD heterogeneity in the ECLIPSE cohort. Respir Res. 2010;11:122. doi: http://dx.doi.org/10.1186/1465-9921-11-122

2. Global initiative for Chronic Obstructive Lung Disease (GOLD). Global strategy for the diagnosis, management, and prevention of chronic obstructive pulmonary disease. Updated 2016. GOLD website. http://wwwgoldcopdorg/uploads/users/files/ WatermarkedGlobal\%20Strategy\%202016(1)pdf2016 Accessed: February 5, 2016. Published: 2016.

3. Postma DS, Anzueto AR, Jenkins C, et al. Factor analysis in predominantly severe COPD: identification of disease heterogeneity by easily measurable characteristics. Respir Med. 2013;107(12):1939-1947.

doi: http://dx.doi.org/10.1016/j.rmed.2013.07.011

4. Jones PW, Donohue JF, Nedelman J, Pascoe S, Pinault G, Lassen C. Correlating changes in lung function with patient outcomes in chronic obstructive pulmonary disease: a pooled analysis. Respir Res. 2011;12:161.

doi: http://dx.doi.org/10.1186/1465-9921-12-161

5. Donohue JF, Jones P, Bartels C, et al. Relationship between change in trough $\mathrm{FEV}_{1}$ and COPD patient outcomes: pooled analysis of 23 clinical trials in patients with COPD. Abstract presented at: the 25th European Respiratory Society Annual Congress; September 26-30, 2015; Amsterdam, The Netherlands

6. Cazzola M, MacNee W, Martinez FJ, et al. Outcomes for COPD pharmacological trials: from lung function to biomarkers. Eur Respir J. 2008;31(2):416-469.

doi: http://dx.doi.org/10.1183/09031936.00099306

7. Mahler DA, Weinberg DH, Wells CK, Feinstein AR. The measurement of dyspnea. Contents, interobserver agreement, and physiologic correlates of two new clinical indexes. Chest. 1984;85(6):751-758.

8. Mahler DA, Wells CK. Evaluation of clinical methods for rating dyspnea. Chest. 1988;93(3):580-586.

9. Chhabra SK, Gupta AK, Khuma MZ. Evaluation of three scales of dyspnea in chronic obstructive pulmonary disease. Ann Thorac Med. 2009;4(3):128-132.

doi: http://dx.doi.org/10.4103/1817-1737.53351

10. Camargo LA, Pereira CA. Dyspnea in COPD: beyond the modified Medical Research Council scale. J Bras Pneumol. 2010;36(5):571-578.

doi: http://dx.doi.org/10.1590/S1806-37132010000500008

11. Sanchez FF, Faganello MM, Tanni SE, Lucheta PA, Padovani CR, Godoy I. Relationship between disease severity and quality of life in patients with chronic obstructive pulmonary disease. Braz J Med Biol Res. 2008;41(1):860-865.

doi: http://dx.doi.org/10.1590/S0100-879X2008005000043
12. Oga T, Nishimura K, Tsukino M, Hajiro T, Mishima M. Dyspnoea with activities of daily living versus peak dyspnoea during exercise in male patients with COPD. Respir Med. 2006;100(6):965-971.

doi: http://dx.doi.org/10.1016/j.rmed.2005.10.006

13. Eakin EG, Sassi-Dambron DE, Ries AL, Kaplan RM. Reliability and validity of dyspnea measures in patients with obstructive lung disease. Int J Behav Med. 1995;2(2):118-134.

14. Bateman ED, Ferguson GT, Barnes N, et al. Dual bronchodilation with QVA 149 versus single bronchodilator therapy: the SHINE study. Eur Respir J. 2013;42(6):1484-1494. doi: http://dx.doi.org/10.1183/09031936.00200212

15. Vogelmeier CF, Bateman ED, Pallante J, et al. Efficacy and safety of once-daily QVA149 compared with twice-daily salmeterolfluticasone in patients with chronic obstructive pulmonary disease (ILLUMINATE): a randomised, double-blind, parallel group study. Lancet Respir Med. 2013;1(1):51-60. doi: http://dx.doi.org/10.1016/S2213-2600(12)70052-8

16. Mahler DA, Palange P, Iqbal A, Owen R, Higgins M, Kramer B. Indacaterol once-daily improves dyspnea in COPD patients: a 26-week placebo-controlled study with open-label tiotropium comparison. Eur Respir J. 2009;34(Suppl. 53):779s (Abstract E4360).

17. Witek TJ, Jr., Mahler DA. Minimal important difference of the transition dyspnoea index in a multinational clinical trial. Eur Respir J. 2003;21(2):267-272.

doi: http://dx.doi.org/10.1183/09031936.03.00068503a

18. Jones PW. St. George's Respiratory Questionnaire: MCID. COPD. 2005;2(1):75-79.

19. Kerstjens HA, Deslée G, Dahl R, et al. The impact of treatment with indacaterol in patients with COPD: A post-hoc analysis according to GOLD 2011 categories A to D. Pulm Pharmacol Ther. 2015;32:101-108.

doi: http://dx.doi.org/10.1016/j.pupt.2015.02.008

20. Price D, West D, Brusselle G, et al. Management of COPD in the UK primary-care setting: an analysis of real-life prescribing patterns. Int J Chron Obstruct Pulmon Dis. 2014;9:889-905. doi: http://dx.doi.org/10.2147/COPD.S62750

21. Dransfield MT, Bailey W, Crater G, Emmett A, O’Dell DM, Yawn B. Disease severity and symptoms among patients receiving monotherapy for COPD. Prim Care Respir J. 2011;20(1):46-53. doi: http://dx.doi.org/10.2147/COPD.S62750

22. Mahler DA, Decramer M, D'Urzo A, et al. Dual bronchodilation with QVA149 reduces patient-reported dyspnoea in COPD: BLAZE study. Eur Respir J. 2014;43(6):1599-1609. doi: http://dx.doi.org/10.1183/09031936.00124013 
23. Jenkins CR, Jones PW, Calverley PM, et al. Efficacy of salmeterol/fluticasone propionate by GOLD stage of chronic obstructive pulmonary disease: analysis from the randomised, placebo-controlled TORCH study. Respir Res. 2009;10:59. doi: http://dx.doi.org/10.1186/1465-9921-10-59

24. Donohue JF, Maleki-Yazdi MR, Kilbride S, Mehta R, Kalberg C, Church A. Efficacy and safety of once-daily umeclidinium/ vilanterol 62.5/25 mg in COPD. Respir Med. 2013;107(1):15381546. doi: http://dx.doi.org/10.1016/j.rmed.2013.06.001

25. Decramer M, Anzueto A, Kerwin E, et al. Efficacy and safety of umeclidinium plus vilanterol versus tiotropium, vilanterol, or umeclidinium monotherapies over 24 weeks in patients with chronic obstructive pulmonary disease: results from two multicentre, blinded, randomised controlled trials. Lancet Respir Med. 2014;2(6):472-486.

doi: http://dx.doi.org/10.1016/S2213-2600(14)70065-7

26. Singh D, Jones PW, Bateman ED, et al. Efficacy and safety of aclidinium bromide/formoterol fumarate fixed-dose combinations compared with individual components and placebo in patients with COPD (ACLIFORM-COPD): a multicentre, randomised study. BMC Pulm Med. 2014;14:178. doi: http://dx.doi.org/10.1186/1471-2466-14-178

27. D’Urzo AD, Rennard SI, Kerwin EM, Mergel V, Leslbaum AR, Caracta CF. Efficacy and safety of fixed-dose combinations of aclidinium bromide/formoterol fumarate: the 24-week, randomized, placebo-controlled AUGMENT COPD study. Respir Res. 2014;15:123.

doi: http://dx.doi.org/10.1186/s12931-014-0123-0

28. Beeh KM, Westerman J, Kirsten AM, et al. The 24-h lungfunction profile of once-daily tiotropium and olodaterol fixeddose combination in chronic obstructive pulmonary disease. Pulm Pharmacol Ther. 2015;32:53-59.

doi: http://dx.doi.org/10.1016/j.pupt.2015.04.002

29. Buhl R, Maltais F, Abrahams R, et al. Tiotropium and olodaterol fixed-dose combination versus mono-components in COPD (GOLD 2-4). Eur Respir J. 2015;45(6):969-979. doi: http://dx.doi.org/10.1183/09031936.00136014

30. Chapman K, Bateman E, Gallagher N, Hu H, Banerji D. QVA149 once daily improves lung function, dyspnoea and health status independent of prior medications and disease severity: the SHINE study. Thorax. 2013;68:A182-A183 (Abstract P234).

31. Vestbo J, Vogelmeier C, Small M, Higgins V. Understanding the GOLD 2011 Strategy as applied to a real-world COPD population. Respir Med. 2014;108(5):729-736. doi: http://dx.doi.org/10.1016/j.rmed.2014.03.002

32. Jochmann A, Neubauer F, Miedinger D, et al. General practitioners' adherence to the COPD GOLD guidelines:baseline data from the Swiss COPD Cohort Study. Swiss Med Wkly. 2010;140:W13053.
33. Jebrak G. [COPD routine management in France: are guidelines used in clinical practice?]. Rev Mal Respir. 2010;27(1):11-18. doi: http://dx.doi.org/10.1016/j.rmr.2009.08.002

34. Fitch K, Iwasaki K, Pyenson B, Plauschinat C, Zhang J. Variation in adherence with Global initiative for chronic Obstructive Lung Disease (GOLD) drug therapy guidelines: a retrospective actuarial claims data analysis. Curr Med Res Opin. 2011;27(7):1425-1429.

doi: http://dx.doi.org/10.1185/03007995.2011.583230

35. Bourbeau J, Sebaldt RJ, Day A, et al. Practice patterns in the management of chronic obstructive pulmonary disease in primary practice: the CAGE study. Can Respir J. 2008;15(1):1319.

36. Roche N, Pribil C, Van Ganse E, et al. Real-life use of fluticasone propionate/salmeterol in patients with chronic obstructive pulmonary disease: a French observational study. BMC Pulm Med. 2014;14:56. doi: http://dx.doi.org/10.1186/1471-2466-14-56

37. Singh D, Maleki-Yazdi MR, Tombs L, Naya I, Church A, Iqbal A. Can dual long-acting bronchodilator therapy prevent clinically important deteriorations in chronic obstructive pulmonary disease? A post hoc analysis of the ZEP117115 trial. Am J Respir Crit Care Med. 2015;191(1):A5760.

38. Jones PW, Beeh KM, Chapman KR, Decramer M, Mahler DA, Wedzicha JA. Minimal clinically important differences in pharmacological trials. Am J Respir Crit Care Med. 2014;189(3):250-255.

doi: http://dx.doi.org/10.1164/rccm.201310-1863PP 